\title{
Avaliação da qualidade percebida de um serviço por meio de site de redes sociais
}

\author{
Evaluation of perceived quality service by site of \\ social networks
}

\author{
Tiago Rodrigues Azevedo ${ }^{1}$ \\ Cristine Hermann Nodari ${ }^{2}$ \\ JuliceSalvagni ${ }^{3}$ \\ Alípio Ramos Veiga Neto ${ }^{4}$
}

\section{Resumo}

O setor de serviços representa a chave para o crescimento da economia e a geração de empregos no Brasil. Mensurar a qualidade da prestação de serviços é essencial para a evolução do setor. O fenômeno de crescimento dos sites de redes sociais, e a aderência de uma parte importante da população, apresentam este meio como oportunidade para a compreensão do consumidor de serviços e como janela para a observação de sua percepção sobre a qualidade de serviços. A proposta deste trabalho foi identificar as cinco dimensões da qualidade de serviços

Especialização em andamento em Master em Marketing, Graduação em Design Gráfico,Uniritter - Laureate International Universities - Brasil - E-mail: tiago.aze@gmail.com

2 Pós-Doutorado, Bolsista do Programa Nacional de Pós-Doutorado da Coordenação de Aperfeiçoamento de Pessoal de Nível Superior (PNPD/CAPES). Doutora em Administração pela Pontifícia Universidade Católica do Rio Grande do Sul (PUCRS), Brasil e pela Universidade de Caxias do Sul (UCS) Brasil, Bolsista do Programa de Suporte à Pós-Graduação de Instituições de Ensino Particulares da Coordenação de Aperfeiçoamento de Pessoal de Nível Superior (PROSUP/ CAPES). Mestra em Administração pela Universidade de Caxias do Sul (UCS), Brasil. Especialista em Gestão Empresarial pela Fundação Getúlio Vargas (FGV) Brasil. Possui experiência gerencial em multinacional. Principais temas de interesse e linhas de pesquisa: Gestão da Inovação, Competitividade e Mercado. Atualmente, é professora do Mestrado Acadêmico em Administração da Universidade Potiguar - Brasil - E-mail: cristine.nodari@gmail.com

3 Doutoranda em Sociologia (UFRGS/CAPES - 2012). Mestre em Ciências Sociais (Unisinos- 2011), Especialista em Gestão Empreendedora (Ftec- 2009) e Psicóloga (Unisinos- 2007). Atuou como docente da Universidade de Caxias do Sul e como psicóloga clínica e do trabalho. Atualmente, é professora dos cursos de pós-graduação da Faculdade São Judas Tadeu e Uni Ritter Laureate International Universities - Brasil - Email: julicesalvagni@gmail.com

4 Doutor em Psicologia pela PUC-Campinas, Mestrado em Psicologia Educacional, Graduado em Psicologia com Licenciatura e Bacharelado. Pós-Graduado em Marketing pela ESPM (latosensu) e Tecnólogo Industrial pela Unimep. Atualmente pesquisa, Mídias Sociais, Marketing Verde, Inovação, Estratégia como Prática (ECP), e o Comportamento do Consumidor com base nas teorias do behaviorismo radical e Psicologia Evolutiva, Universidade Potiguar - Laureate Universities International - Brasil - E-mail: alipio.veiga@gmail.com 
em postagens feitas pelos consumidores de um restaurante em sua página em um site de redes sociais. Estas postagens tiveram seu conteúdo analisado em busca de aglomerados semânticos que pudessem ser categorizados dentro destas dimensões. Os resultados, validados através do modelo de lacunas da qualidade de serviços, demonstram que os sites de redes sociais figuram como importante fonte de informações para empresas acerca das expectativas, percepções e satisfação de seus clientes. Ainda se destacaram limitações quanto à baixa padronização dos dados oriundos das redes sociais, e a heterogeneidade de comportamento dos consumidores a respeito de diferentes marcas. $\mathrm{O}$ artigo revela oportunidades para novos estudos tanto no campo da qualidade de serviços percebida quanto na exploração dos sites de redes sociais como fonte de dados para novas pesquisas.

Palavras-chave: Redes Sociais. Qualidade de Serviços. Marketing de Serviços.

\section{Abstract}

The service sector is the key to economic growth and job creation in Brazil. Measure the quality of service provision is essential to the development of the sector. The growing phenomenon of social networking sites, and the grip of a major part of the population have this medium as an opportunity for understanding the consumer of services and how the window for observing their perception of the quality of services. The purpose of this study was to identify the five dimensions of service quality in posts made by consumers of a restaurant on your page on a social networking site. These posts were content analyzed for semantic clusters that could be categorized within these dimensions. The results validated through the model of service quality gaps show that the social networking sites appear as an important source of information for companies about the expectations, perceptions and satisfaction of its customers. Still stood out limitations on the low standardization of data from social networks, and consumer behavior of heterogeneity regarding different brands. The article reveals opportunities for further studies both in the field of service quality perceived as the exploitation of social networking sites as a source of data for further research.

Keywords: Social Networks. Service quality. Marketing Services.

\section{Introdução}

No Brasil, cerca de 76 milhões de pessoas têm acesso ao Facebook; isso o posiciona como o terceiro país em número de usuários ativos nessa mídia social. De acordo com dados do site Socialbakers, das cinco marcas brasileiras com maior número de seguidores no 
Facebook, quatro são do setor alimentício. Isso mensura a quantidade de pessoas interessadas na mensagem da marca em um ambiente onde a comunicação com os consumidores é facilitada. As redes sociais acabam desempenhando um papel fundamental nessa aproximação das empresas com seu público. São espaços nos quais as organizações permitem às pessoas que dela fazem ou sentem fazer parte o seu momento de fala. É o ambiente em que as trocas de impressões acerca da empresa e seu posicionamento são incentivados e apreciados. A marca deixa de ser construída apenas através de seus anúncios publicitários e seus canais de comunicação formais, e passa a ser tangibilizada pelas impressões de seus públicos, bem como suas histórias com ela.

O setor de alimentação fora do lar é especialmente sensível a esse tipo de interação nas mídias sociais, no caso de restaurantes, segundo Kimes (2011), muitos confiam nas recomendações feitas por outros usuários na hora de escolher um local para suas refeições. Muitos consumidores revelam nas redes sociais a qualidade de serviço percebida, que pode ser definida como o grau e a direção da discrepância entre a percepção e a expectativa do consumidor (PARASURAMAN; BERRY; ZEITHAML, 1988).

Diversos estudos apontam a percepção da qualidade de serviço como fator chave de sucesso para as empresas (COBRA, 2009; KOTLER; KELLER, 2012; LOVELOCK; WIRTZ, 2006; ZEITHAML; BITNER; GREMLER, 2014;) e outros fazem a ligação entre a qualidade de serviço e a percepção da marca (BRITO, 2010; KELLER, 2003). A importância do boca a boca na formação das expectativas dos clientes também é objeto de diversos trabalhos (KOTLER; KELLER, 2012; ZEITHAML; BITNER; GREMLER, 2014) e, finalmente, o potencial multiplicador desse boca a boca através das redes sociais na internet é amplamente discutido em livros e artigos (CIPRIANI, 2012; GIARDELI, 2011;KIMES, 2011; RECUERO, 2009).

A presente investigação teve como objeto de estudo uma organização do ramo da alimentação fora do lar. Essa empresa atua no mercado há mais de 15 anos e conta com cerca de 300 lojas franqueadas dentro e fora do território nacional. No final do ano de 2014, a página da 
empresa no Facebook contava com mais de 230 mil curtidas, estando a mesma dentro do ranking das 20 empresas com maior número de fãs na categoria de restaurantes no Brasil.

Nesse sentido, a questão norteadora desta pesquisa foi: como se apresenta a qualidade de serviço percebida, nas redes sociais, do estudo de caso? Assim, a pesquisa teve por objetivo geral analisar a qualidade percebida pelos consumidores, por meio da página do Facebook, de uma organização pertencente a uma importante rede de restaurantes. Os objetivos específicos que sustentaram o objetivo geral foram (1) identificar as características das postagens, e (2) identificar e analisar as vantagens e as dificuldades elencadas pelos consumidores compondo agrupamentos semânticos relacionados às dimensões da qualidade identificadas por Parasuraman, Berry e Zeithaml (1991).

A relevância da pesquisa encontra-se no desenvolvimento e manutenção de competitividade das organizações, com a insurgência da comunicação virtual. Atualmente, tornou-se essencial que as organizações estabeleçam as redes sociais como fonte de informações das expectativas dos clientes. Oferecer produtos e serviços alicerçados no componente da qualidade passou a ser condição de preexistência no mercado, não mais configurando como um aspecto de diferenciação (DU et al., 2015; FACl et al., 2015).

O presente trabalho seguiu com um aprofundamento do conceito de qualidade de serviço percebida e uma apresentação do contexto das redes sociais. Em seguida, foi apresentada a metodologia de pesquisa que conduziu a próxima seção referente à análise dos resultados. A seção final foi dedicada à conclusão do estudo e às limitações e sugestões para o desenvolvimento do tema.

\section{Referencial teórico}

\subsection{Qualidade de serviço percebida}

Kotler e Keller (2012) definem serviços como qualquer ato ou desempenho, essencialmente intangível, que uma parte pode oferecer 
a outra e que não resulta na propriedade de nada e ressalta que a execução de um serviço pode ou não estar ligada a um bem concreto. Sendo assim o serviço pode ser apenas parte da oferta total.

Ao tratarmos sobre o mix de marketing em serviços é importante reconhecer que além dos tradicionais elementos como produto, ponto, promoção e preço, é necessário adicionar ao mix elementos essenciais como pessoas, evidência física e processos. Estes três elementos influenciam diretamente na percepção do comprador em relação ao serviço e são, portanto, essenciais (ZEITHAML; BITNER; GREMLER, 2014).

Restaurantes se caracterizam como serviços híbridos uma vez que o produto final, composto pela refeição, depende de uma série de serviços intangíveis que vão desde o atendimento prestado pelo garçom, passam pelo preparo do alimento, chegando até a entrega da conta. Tanto o consumo do produto quanto os serviços de um restaurante exigem a presença do cliente para acontecer, sendo assim a qualidade destes serviços, assim como do produto entregue afetam a percepção do cliente sobre a entrega e, consequentemente, sua satisfação. Vivemos em uma realidade onde a diferenciação através do produto é cada vez mais difícil. Por isso, apostar na qualidade de serviços como forma de oferecer uma experiência memorável para o consumidor é a melhor forma de atingir um diferencial competitivo (KOTLER; KELLER, 2012).

Em um restaurante, prevalecem as qualidades experimentáveis que são as que podem ser percebidas pelo cliente no momento da experiência do serviço, diferente das qualidades pesquisáveis que são objetivas e não dependem do julgamento pessoal, como peso, cor, tamanho etc. (KOTLER; KELLER, 2012; ZEITHAML; BITNER; GREMLER, 2014).

Diferente do consumo de produtos, os serviços são gerados e consumidos ao mesmo tempo. A satisfação do cliente nesse caso depende de fatores que ocorrem em tempo real, como a interação com funcionários e outros clientes. Produção e consumo simultâneos também abrem portas para modelos de serviço nos quais o consumidor 
é parte do processo de produção, possibilitando a customização da oferta. (ZEITHAML; BITNER; GREMLER, 2014).

Brito (2010) sumariza a questão das associações decorrentes da experiência com a prestação de serviços conforme o seguinte excerto:

As associações à marca, em particular na área dos serviços, resultam, em larga medida, do processo de interação entre os clientes e os colaboradores da empresa. Dessa forma, estes são um elemento central na criação da imagem da marca - bem como na sua destruição... Empresas com marcas fortes são aquelas que reconhecem que o valor da marca começa a ser construído de dentro para fora, no sentido de que se os clientes internos - ou seja, os colaboradores - não comprarem o conceito da marca, dificilmente os clientes externos o farão. (BRITO, 2010, p. 49-63).

É inegável a importância do setor de serviços na geração de riqueza e emprego para o país. Segundo dados do Instituto Brasileiro de Geografia e Estatística (IBGE, 2014), entre 2004 e 2013 os serviços cresceram a uma taxa média de 3,8\% a.a. (contra 3,0\% a.a. da agropecuária e 2,8\% a.a. da indústria). A participação dessas atividades no Produto Interno Bruto (PIB) do Brasil chegou a 69,4\% em 2013. Dados da Relação Anual de Informações Sociais (RAIS) revelam que em 2012 os serviços responderam por $72,7 \%$ dos 47,5 milhões de empregos formais registrados no país. A Pesquisa Anual de Serviços (PAS) 2010, divulgada pelo IBGE (2014), revelou que as 992808 empresas cuja atividade principal integrava o âmbito da pesquisa obtiveram $\mathrm{R} \$ 869,3$ bilhões de receita operacional líquida e $\mathrm{R} \$ 510,4$ bilhões de valor adicionado, ocuparam 10622 mil pessoas e despenderam R $\$ 172,5$ bilhões em remunerações. Os serviços de alimentação, no qual estão incluídos os restaurantes, destacaram-se como a principal atividade em termos de geração de receita, valor adicionado, massa salarial, pessoal ocupado e número de empresas. Em 2010, as 193309 empresas da atividade obtiveram $\mathrm{R} \$ 55,7$ bilhões de receita operacional líquida, ocuparam 1 398 mil pessoas e pagaram R $\$ 13,1$ bilhões em remunerações. 
O Brasil possui dois índices nacionais de satisfação sendo eles o Índice Brasileiro de Satisfação do Cliente (BCSI) que utiliza a metodologia do American CustomerSatisfaction Index (ACSI) e o Índice Nacional de Satisfação do Consumidor (INSC) que utiliza uma metodologia diferente para avaliar quesitos semelhantes, sendo eles a qualidade percebida, a expectativa dos clientes e o valor percebido. Ambos avaliam apenas as principais empresas de alguns setores específicos da economia e por isso servem mais para dar um panorama macro da satisfação do consumidor brasileiro. O BSCI não apresenta nenhum resultado referente ao setor da Alimentação e o INSC, embora apresente, refere-se apenas às quatro maiores fabricantes de produtos alimentícios atuantes no mercado nacional, não refletindo assim a satisfação do consumidor brasileiro em relação a restaurantes. O ACSI realizado nos Estados Unidos apresenta dados históricos sobre a satisfação do consumidor americano em relação aos serviços de restaurantes desde 1994, sendo possível avaliar assim a evolução da qualidade destes serviços ao longo dos anos. Os dados americanos indicam que, em 2014, o consumidor apresentou $80 \%$ de satisfação em relação a Restaurantes de Serviço Limitado. Em 1994, esse índice era de $69 \%$ havendo assim uma significativa melhora de $15,9 \%$.

A Teoria da Desconfirmação das Expectativas descrita por Oliver (1980) para explicar a satisfação dos consumidores permanece válida. Segundo essa teoria, o cliente compara a percepção que teve do serviço com a expectativa criada sobre o mesmo. A desconfirmação surge da diferença entre estes dois fatores. Para Martensen e Grønholdt (2004), o encantamento ocorre quando a percepção supera a expectativa; a satisfação ocorre quando os dois fatores se igualam; e a insatisfação surge quando a percepção é pior do que a expectativa.

Parasuraman, Berry e Zeithaml (1985) defendem um modelo de lacunas da qualidade de serviços para explicar as principais causas de insatisfação dos clientes em relação aos serviços. A lacuna um (Gap 1) representa a diferença entre o serviço esperado pelo consumidor e a percepção da empresa sobre esta expectativa, a empresa muitas vezes falha ao tentar entender o que o cliente espera de um serviço e 
se concentra mais em fatores internos de qualidade, como produtividade e ausência de defeitos físicos no produto. A lacuna dois (Gap 2)é a que surge da diferença entre as percepções da empresa sobre as expectativas do cliente e os padrões e projetos de serviços definidos de acordo com as expectativas do cliente. A lacuna três (Gap 3) representa a diferença entre estes padrões e a execução de serviços, esta lacuna pode ser exemplificada pela dificuldade de funcionários em cumprir os padrões definidos pela empresa. A lacuna quatro (Gap 4) refere-se à distância entre o que é comunicado para o cliente e o que é entregue, ela afeta diretamente as expectativas do cliente. A lacuna cinco (Gap 5) representa a diferença entre o serviço esperado pelo cliente e a sua percepção sobre o serviço recebido, conforme demonstra a Figura 1, retomado posteriormente na análise dos resultados encontrados pela pesquisa.

A administração de serviços propõe uma nova urgência quanto à maneira de encarar o cliente. Em um estabelecimento de prestação de serviços, clientes satisfeitos são como ativos. As compras futuras dos clientes possuem um valor presente que faz parte do capital intangível do empreendimento. Essa visão de Fitzsimmons e Fitzsimmons (2005) demonstra que se pode pensar no cliente como um ativo que se valoriza, ou seja, um ativo cujo valor aumenta com o passar do tempo, e isso é realmente o que se verifica quando a satisfação e a lealdade do cliente estão em um processo ascendente.

O serviço esperado tem a ver com as expectativas do cliente, que podem ser influenciadas pela própria empresa, por experiências anteriores ou por fatores externos diversos. Estas possuem uma escala que vai da mais alta a mais baixa em uma zona de tolerância. No patamar mais alto estão as expectativas ideais, que representam uma experiência idealizada de serviço perfeito, seguidas por expectativas normativas que esperam alto padrão de serviços baseado em indicadores como preço, as próximas são as expectativas baseadas em experiência, em que o consumidor já conhece o padrão de serviço, as penúltimas são as expectativas aceitáveis onde não é esperado nada além de um serviço 
adequado e as últimas são as expectativas mínimas dentro do tolerável (ZEITHAML; BITNER; GREMLER, 2014).

Figura 1 - Modelo de lacunas em serviços

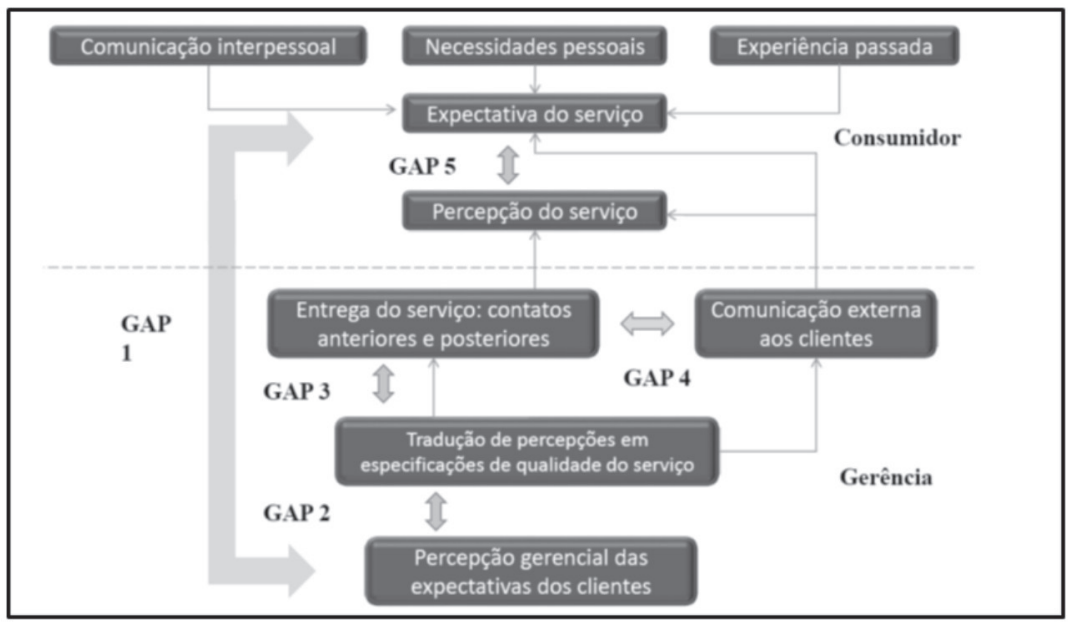

Fonte: Adaptado de Parasuraman, Berry e Zeithaml (1991, p.446-449).

A qualidade de serviço percebida é avaliada pelo cliente por meio de cinco dimensões que influenciam em sua percepção sendo elas: a confiabilidade que representa a capacidade da empresa em prestar o serviço de forma precisa e confiável; a responsividade que está ligada a rapidez no serviço e a disposição em atender de forma ágil; a segurança, representada pela cortesia e grau de conhecimento inspirado pelo funcionário; a empatia que concerne à atenção individualizada oferecida ao cliente e a tangibilidade, referente a equipamentos, instalações e outras provas físicas de qualidade (LOVELOCK et al., 2014; WIRTZ, 2006).

\subsection{Sites de redes sociais}

Embora seja corriqueiro o uso do termo redes sociais para designar ferramentas virtuais como o Facebook, este é na verdade constituído por 
diversas redes sociais formadas pelos atores sociais que ali interagem. Sites de redes sociais são ferramentas de comunicação mediada pelo computador que facilitam os processos interacionais, permitindo aos usuários articular e exibir suas redes sociais (BOYD; ELLISON, 2008; RECUERO, 2009). Os sites de redes sociais podem ser definidos como sistemas virtuais que permitem a (1) construção de perfis públicos ou semipúblicos dentro de um sistema fechado; (2) a articulação de uma lista de outros usuários com os quais possui conexão; e (3) a visualização e transversalização de sua lista de conexões com aquelas feitas por outros dentro do sistema (BOYD; ELLISON 2008).

Atualmente, o Facebook é o site de redes sociais com maior número de usuários no mundo. Segundo dados do site Socialbakers, são mais de 1.350 .000 de usuários ativos por mês. O Brasil figura como terceiro colocado em número de usuários com 76 milhões de usuários ativos por mês. Dentro da categoria de restaurantes, as marcas com maior número de fãs no mundo são McDonald's com 55.406.389 fãs, Starbucks com 38.071.055 fãs e KFC com 36.665.895 fãs.

As marcas com maior número de fãs brasileiros no Facebook, na categoria de restaurantes, são as marcas internacionais McDonald's, com 5.989.564 fãs; Subway Brasil, com 5.285.183 fãs; e Burger King, com 4.441.810 fãs. A primeira marca nacional a aparecer no ranking é o Habib's, em quinto lugar, com 3.458.232 fãs. Esses números demonstram a aderência do consumidor brasileiro aos sites de redes sociais, especialmente ao Facebook.

Segundo Ng e Wang (2013), o Facebook é a empresa top de publicidade de mídia social nos Estados Unidos. Outro estudo realizado por uma empresa de marketing global (LOOMER, 2012), revelou que muitos países do mundo estão escolhendo o Facebook como um nicho para promover seus negócios campanha ou marca, para se comunicar com as partes interessadas, e para atrair seus potenciais clientes; e é um site de mídia social dominante que, potencialmente, tem um grande impacto sobre o comércio social, devido à sua popularidade. 
Para Recuero (2009), coexiste nos sites de redes sociais uma rede de filiação formada, por exemplo, pela "lista de amigos" e uma rede emergente formada pela conversação entre os atores sociais no espaço virtual abarcado pela ferramenta. O valor dessa conversação é explorado por Giardeli (2012), que define a internet não como rede de computadores, mas como software de expressão da sabedoria das multidões. O autor destaca que se conectar e compartilhar são atitudes fundamentais para o ser humano e considera ineficiente a comunicação de marketing feita sem levar em conta o coletivo e as redes sociais.

Cipriani (2011) aponta para uma transformação no consumidor, que passa a participar de forma muito mais ativa na relação com as marcas. Visto que este encontra, no ambiente on-line, uma forma fácil, instantânea e eficaz de divulgar a sua experiência. O resultado dessa transformação é a formação do novo consumidor social. Dentro das redes emergentes, a conversação entre os atores sociais, agora no papel de consumidores, possui um grande potencial multiplicador.

Nesse cenário, Segundo Torres (2009), o consumidor na internet é basicamente o mesmo dos conceitos tradicionais, composto por pessoas com suas necessidades e preferências, porém interagindo no mundo digital e trocando experiências, frustrações, anseios e expectativas mediante canais de comunicação mais ágeis. As ações de marketing digital baseadas no comportamento do consumidor são mais efetivas no alcance da mídia, pois interagem com as pessoas a partir de quatro necessidades básicas que estas buscam suprir: o relacionamento, a informação, a comunicação e a diversão.

O ambiente dos sites de redes sociais é especialmente propício à comunicação viral, onde a mensagem flui por contágio entre os nós da rede social (AGUIAR, 2007). Essa facilidade na propagação da informação se dá principalmente pelas características descritas por Boyd e Ellison (2008) para esse ambiente público mediado pela tecnologia: (1) Persistência refere-se à permanência do que é dito na internet; (2) Capacidade de Busca refere-se à possibilidade de buscar os atores sociais e as informações compartilhadas por eles; (3) Replicabilidade refere-se à facilidade de compartilhar mensagens e espalhar informações 
neste ambiente; (4)Audiências Invisíveis referem-se a todas as possíveis audiências que poderão ter acesso a uma mensagem, mesmo aquelas que não têm participação direta no diálogo ou as que podem aparecer após a publicação da conversação.

Os relatos trocados entre os consumidores sociais nos sites de redes sociais têm forte impacto no desempenho da marca. No caso de restaurantes, segundo Kimes (2011), muitos confiam nas recomendações feitas por outros usuários na internet na hora de escolher um local para suas refeições. Um estudo conduzido pela Nielsen em 2012 apontou que $62 \%$ dos usuários de sites de redes sociais consideram opiniões de outros consumidores como sua fonte preferida de informações sobre um serviço. Sobre os motivos que os levam a dividir suas experiências estes usuários responderam: 61\% para parabenizar a empresa por um serviço bem feito; $58 \%$ para proteger outros consumidores; $32 \%$ para que a empresa Ihes responda; $25 \%$ para punir a empresa.

Estudos como o da Nielsen demonstram que as redes sociais são um meio em que os consumidores compartilham suas experiências com frequência e influenciam nas decisões de consumo uns dos outros. Essa dinâmica de troca de percepções ajuda a construir o posicionamento da marca de forma positiva ou negativa. Para Aaker (1998), essa percepção é intangível, caracteriza-se como um sentimento geral sobre uma marca e está ligada diretamente à decisão de compra. Quando positiva, pode tornar todos os elementos do programa de marketing mais eficazes. Keller (2003) destaca o fato de essa percepção ter relação com a interpretação pessoal de cada consumidor e define assim um conceito de marca válido para o escopo deste artigo, conforme o fragmento a seguir:

Apesar de caber às empresas promoverem a criação da marca através de programas de marketing e outras atividades, em última instância a marca é qualquer coisa que reside na mente dos consumidores. Uma marca, sendo uma entidade perceptiva enraizada na própria realidade, é mais do que isso pois reflete as percepções bem como as idiossincrasias dos consumidores. (KELLER, 2003, p. 13). 
Para Brito (2010), a construção da marca é um processo que envolve os clientes, sem os quais não faz sentido falar em notoriedade, imagem e lealdade, conceitos essenciais no ponto de vista do marketing. O autor destaca, ainda, que um dos pilares do valor de uma marca é a imagem, estando esta assente em um conjunto de percepções que o consumidor associa à organização. No caso de restaurantes, onde além do produto recebido pelo consumidor existe também a prestação de serviço e de atendimento, as percepções do consumidor dependem muito da qualidade desta interação com quem presta o serviço.

Um importante fator a ser destacado no comportamento do consumidor na internet é quanto às regras de uso da rede. Na verdade, elas não existem. As regras são definidas a partir da experiência dos próprios usuários, porém são informais, não escritas. Os usuários de redes sociais, ao formarem seus grupos de interesse ou de afinidades, criam regras internas para serem seguidas pelos usuários interessados no conteúdo, as quais são transmitidas a partir da interação (TORRES, 2009).

A satisfação ou não das expectativas do consumidor muitas vezes resulta em uma busca por parte deste em compartilhar sua experiência nas redes sociais. Comentários feitos publicamente por usuários de redes sociais que recaem na categoria de encantamento são geralmente positivos e dos insatisfeitos com a marca, negativos. O monitoramento destes diálogos de usuários tem valia para marcas que desejam conhecer a percepção de seus consumidores. Para Cipriani (2011), as formas mais usadas para medir desempenho em mídias sociais são quantitativas, incluindo-se o número de seguidores. Poucas empresas utilizam métricas qualitativas mais complexas. O autor destaca que muitos dos benefícios das mídias sociais são qualitativos e difíceis de mensurar, são resultados indiretos do relacionamento estabelecido com os consumidores nas redes sociais e incluem a percepção da marca ou a percepção dos clientes como direcionadores. 


\section{Método}

\subsection{Caracterização do ambiente de pesquisa}

A presente investigação teve como objeto uma empresa do ramo da alimentação fora do lar. Ela atua no mercado há mais de 15 anos e no presente momento conta com cerca de 300 lojas franqueadas dentro e fora do território nacional. No mercado internacional a empresa possui operações em funcionamento no México e na Costa Rica. O negócio faz parte de um grupo detentor de outras marcas do setor de alimentação fora do lar. Em 2013 este grupo apresentou faturamento de $R \$ 732,56$ milhões e 482 lojas. Para 2014, a projeção de faturamento da companhia foi de $\mathrm{R} \$ 885,63$ milhões, com a operação de 574 restaurantes em funcionamento.

A empresa admite estar num mercado intermediário entre o restaurante e o fast-food denominado food service baseado na percepção de um mercado de pessoas que se alimentam fora de casa diariamente, mas que fazem questão de uma refeição de qualidade, sem abrir mão do bom atendimento (PINTO; GOMES, 2010). A direção do restaurante acredita que o lançamento contínuo de produtos, combinados com aspectos de vida saudável levando ao consumidor mais qualidade de vida, são aspectos importantes para a continuidade de expansão da empresa.

No final do ano de 2014, a página da empresa no Facebook contava com mais de 230 mil curtidas, estando dentro do ranking das 20 empresas com maior número de fãs na categoria de restaurantes no Brasil. A empresa possui, ainda, presença no Twitter, com cerca de 9600 seguidores e no Youtube, com aproximadamente 8.400 inscritos em seu canal. A página do Facebook é rica em interações de consumidores com a marca, havendo muitas postagens destes consumidores neste site de redes sociais. São relatos de experiências que estes clientes compartilham com outros clientes e com a própria marca.

A presente pesquisa teve como objetivo analisar a qualidade de serviços percebida pelos clientes dessa rede de restaurantes, utilizando 
como base de dados os comentários realizados pelos consumidores através do site de redes sociais Facebook. Isso foi alcançado através da identificação do alcance da marca no Facebook, a seleção de dados que pudessem revelar a percepção dos clientes em relação à qualidade de serviços e a análise de conteúdo dos dados coletados.

\subsection{Técnicas e procedimentos adotados}

A presente pesquisa caracteriza-se por uma abordagem qualitativa com objetivo exploratório. Segundo Gil (2007), a pesquisa exploratória visa a aumentar a familiaridade sobre determinado tema, tornando-o mais explícito e possibilitando a geração de hipóteses.

O procedimento metodológico adotado é o estudo de caso que permite uma investigação empírica aprofundada sobre um tema contemporâneo dentro do seu contexto de realidade e que preserva as características holísticas e significativas dos eventos da vida real (GIL, 2007; YIN, 2005).

A análise e interpretação dos dados coletados seguiram a técnica da análise de conteúdo, que, para Bardin (2011), designa-se como um conjunto de técnicas de análise e manipulação das comunicações que permitem ao pesquisador evidenciar os indicadores que o permitam inferir sobre as condições de produção dessas mensagens e sobre outra realidade que não a da mensagem.

O estudo iniciou com uma revisão bibliográfica baseada nos objetivos da pesquisa e na caracterização do ambiente. Sendo assim foram revisados livros e artigos que ajudassem a esclarecer o panorama atual dos sites de redes sociais e dar bases para a compreensão teórica sobre as relações entre atores sociais, que ocorrem neste ambiente. Fizeram parte da revisão também conteúdos relacionados ao marketing de serviços e a qualidade de serviço percebida, que formam a base para os indicadores que foram analisados dentro dos sites de redes sociais.

O passo seguinte foi a investigação dos sites de redes sociais onde a empresa objeto deste estudo possuía presença ativa. A página 
da empresa no site de redes sociais Facebook foi selecionada como fonte de dados com maior conteúdo de comunicação de clientes com a marca. Para os fins deste estudo, foram coletadas 66 postagens de junho a setembro de 2014. Nesse período, foram excluídas apenas as postagens de cunho promocional, postagens de funcionários ou com comentários que não tinham relação com a empresa.

Mediante uma leitura flutuante do conjunto de informações coletadas, foram agrupadas ideias semelhantes através da aproximação semântica e sua frequência contabilizada. Esses agrupamentos semânticos foram identificados quanto à direção como positivos ou negativos.

Com base na revisão bibliográfica, foram utilizadas as cinco dimensões da qualidade do serviço (PARASURAMAN; BERRY; ZEITHAML, 1991) como categorias onde estes agrupamentos foram distribuídos. Dentro de cada categoria foram contabilizadas as frequências de ocorrência de cada agrupamento e identificadas como positivas ou negativas chegando a um resultado final para cada agrupamento e para cada categoria. A representação dessa classificação foi demonstrada no Quadro 1.

Quadro 1 - Categorias, agrupamentos e descrição teórica

\begin{tabular}{|l|l|l|}
\hline CATEGORIAS & \multicolumn{1}{|c|}{ AGRUPAMENTOS } & \multicolumn{1}{c|}{ DESCRIÇÃO TEÓRICA } \\
\hline Confiabilidade & $\begin{array}{l}\text { Estoque } \\
\text { Comunicação } \\
\text { Marca } \\
\text { Confiança }\end{array}$ & $\begin{array}{l}\text { Aaker (1998) } \\
\text { Kotler e Keller (2012) } \\
\text { Lovelock; Wirtz (2006) } \\
\text { Zeithaml; Bitner; Gremler(2014) }\end{array}$ \\
\hline Responsividade & Recuperação & $\begin{array}{l}\text { Faci; Petrocchi; Costantino; Martinelli;Maamar } \\
\text { (2015) } \\
\text { Zeithaml; Bitner; Gremler(2014) }\end{array}$ \\
\hline Segurança & $\begin{array}{l}\text { Higiene } \\
\text { Segurança Alimentar }\end{array}$ & $\begin{array}{l}\text { Fitzsimmons;Fitzsimmons (2005) } \\
\text { Grönroos (2009); }\end{array}$ \\
\hline \multirow{2}{*}{ Empatia } & $\begin{array}{l}\text { Atendimento } \\
\text { Respeito/Educação/Cortesia } \\
\text { Adaptabilidade }\end{array}$ & $\begin{array}{l}\text { Kotler e Keller (2012) } \\
\text { Parasuraman; Berry;Zeithaml (1991) } \\
\text { Zeithaml; Bitner; Gremler(2014) }\end{array}$ \\
\hline & $\begin{array}{l}\text { Produto } \\
\text { Padronização (produtos) }\end{array}$ & $\begin{array}{l}\text { Aaker (1998) } \\
\text { Kotler e Keller (2012) } \\
\text { Lovelock; Wirtz (2006) } \\
\text { Zeithaml; Bitner; Gremler(2014) }\end{array}$ \\
\hline
\end{tabular}

Fonte: Elaboração própria. 
A categoria "confiabilidade" foi subdividida nos agrupamentos (1) estoque, representando a capacidade da empresa de entregar os produtos e ingredientes anunciados, sem apresentar a falta de nenhum deles; (2) comunicação, representando as promessas feitas pela empresa através de sua comunicação externa, em anúncios em quaisquer mídias, em material promocional no ponto de venda e quaisquer outros canais que utilize para se comunicar com seu público; (3) marca, representando o conjunto intangível composto pelas impressões e percepções dos consumidores em relação à empresa; e (5) confiança, representando o quanto o consumidor acredita que está sendo tratado com justiça e recebendo valor ao comprar o produto ou serviço da empresa.

A categoria "responsividade" foi subdividida em (1) recuperação, representando a capacidade e velocidade da resposta da empresa quando algo dá errado em relação ao encontro de serviço.

A categoria "segurança" foi subdividida em (1) higiene, representando o aspecto geral de limpeza tanto dos utensílios, do próprio ponto de venda, dos funcionários e também do produto final; e (2) segurança alimentar, representando o cuidado da empresa em seguir todas as normas de segurança para garantir um produto saudável, fresco e preparado de forma segura.

A categoria "empatia" foi subdividida em (1) atendimento, representando a capacidade do pessoal de linha de frente de prestar um serviço adequado para o consumidor, demonstrando simpatia, atitude positiva e interesse em encantar; (2) respeito/educação/cortesia, representando a forma de se portar do atendente, incluindo seu linguajar, a forma como trata clientes e colegas durante o encontro de serviço e sua cortesia em relação ao cliente e (3) adaptabilidade, representando a capacidade do pessoal de linha de frente em se adequar a pedidos especiais do cliente, seja por necessidade, ou seja, por desejos específicos que tornam o encontro de serviço diferente da regra geral.

A categoria "tangíveis" foi subdividida em (1) produto, representando o resultado final do encontro de serviço, que no caso do restaurante é a refeição, seu sabor, aroma e apresentação; (2) 
padronização dos produtos, representando a uniformidade entre os diferentes pontos de venda em relação a refeição, os ingredientes, seu sabor, aroma e apresentação; e (3) padronização das lojas, representando a uniformidade entre os diferentes pontos de venda em relação a arquitetura, capacidade, comunicação e estrutura física.

\section{Resultados e discussão}

A pesquisa revelou resultados que foram apresentados seguindo as cinco dimensões da Qualidade de Serviço que serviram de categorias para a análise de conteúdo das postagens coletadas no Facebook.

A confiabilidade é a capacidade da empresa de entregar suas promessas para o consumidor no encontro de serviço (ZEITHAML; BITNER; GREMLER, 2014). Os resultados apontam para uma percepção muito negativa dos consumidores em relação a essa capacidade, conforme observado na Tabela 1.

Tabela 1 - Resultados obtidos na categoria confiabilidade

\begin{tabular}{lccc}
\hline & Positivo & Negativo & Resultado \\
\hline Estoque & 0 & 6 & -6 \\
Comunicação & 1 & 5 & -4 \\
Marca & 2 & 1 & +1 \\
Confiança & 0 & 7 & -7 \\
\hline TOTAL & 3 & 19 & -16 \\
\hline
\end{tabular}

Fonte: Elaboração própria.

Em seis comentários analisados, a reclamação sobre estoque surgiu como fator determinante influenciando de forma negativa a percepção do consumidor. O comentário a seguir exemplifica esse agrupamento semântico:

[...] Obrigado pelo mal atendimento no terminal Tietê, além da falta das torradas, ervas frescas e azeite! [...] (Jun/2014). 
Em cinco comentários, a comunicação da empresa foi percebida de forma negativa e de forma positiva em apenas um, geralmente estas manifestações citavam a propaganda enganosa como fonte do problema. O distanciamento entre a comunicação e a entrega dos serviços gera expectativas que irão influenciar a percepção (PARASURAMAN; BERRY; ZEITHAML, 1985). Um exemplo de postagem com essa temática:

[...] Não adianta fazer ação publicitária sobre o atendimento de vocês se não houver mudança real. [...] (Jul/2014).

A marca da empresa surgiu em três comentários, sendo dois deles positivos. A percepção da marca faz parte também da promessa da empresa e está ligada diretamente a decisão de compra (AAKER, 1988; KELLER, 2003), como neste exemplo de comentário coletado:

[...] Aí cai logo salário para que eu possa gastar tudo novamente com este restaurante. (...) (Jun/2014).

A confiança é um sentimento geral de que a empresa está tratando o consumidor com justiça. Para Zeithaml, Bitner e Gremler (2014), o senso de que está sendo tratado de forma justa influencia na satisfação do consumidor com o serviço. Em sete comentários analisados, o resultado foi negativo, como no exemplo a seguir:

[...] Enquanto os preços dos pratos e sanduíches das cadeias de "fastfood" aumentam, as quantidades servidas diminuem...Nas filiais do restaurante, especializado em massas, por exemplo, o envelope com queijo ralado que acompanha as refeições passou a ter minúsculos $10 \mathrm{~g} ! ! !$ [...] (Set/2014).

A responsividade representa a prontidão com que os problemas são resolvidos, bem como a rapidez na prestação do serviço. A recuperação, que referencia a resposta da empresa frente a um problema apontado pelo consumidor, apresentou sete resultados negativos, conforme apresentado na Tabela 2 e exemplificado pelo seguinte trecho de transcrição: 
[...] Dia 03/07 tinha feito a reclamação sobre a filial do shopping metropolitano no RJ. Não recebi o retorno de vocês e ao voltar a filial hoje permanece o mesmo problema. As $16 \mathrm{~h}$ não tinha nem bacon nem gorgonzola. Assim está difícil. [...] (Ago/2014).

Tabela 2 - Resultados obtidos na categoria responsividade

\begin{tabular}{lccc}
\hline & Positivo & Negativo & Resultado \\
\hline Recuperação & 0 & 7 & -7 \\
TOTAL & 0 & 7 & -7 \\
\hline
\end{tabular}

Fonte: Elaboração própria.

A segurança representa o quanto o consumidor confia nos conhecimentos e nas habilidades da empresa para garantir uma boa prestação de serviços e seus resultados estão representados na Tabela 3.

Observou-se que a higiene foi mencionada sete vezes com conotação negativa e uma vez de forma positiva, como no exemplo a seguir:

[...] Este foi o primeiro par de talheres que recebi ontem no restaurante da Galeria São Luiz no Largo do Machado, claro que troquei por outros mas me arrependi de ter ficado e comido pensando em como as estações de trabalho devem ser limpas se os talheres são oferecidos aos clientes em tal estado. [...] (Ago/2014).

Tabela 3 - Resultados obtidos na categoria segurança

\begin{tabular}{lccc}
\hline & Positivo & Negativo & Resultado \\
\hline Higiene & 1 & 7 & -6 \\
Segurança (Alimentos) & 0 & 2 & -2 \\
\hline TOTAL & $\mathbf{1}$ & $\mathbf{9}$ & $\mathbf{- 8}$ \\
\hline
\end{tabular}

Fonte: Elaboração própria. 
A segurança alimentar foi mencionada duas vezes destacando aspectos negativos, representando a falta de certeza do consumidor em relação à capacidade da empresa de garantir seus alimentos, como no exemplo a seguir:

[...] Almocei na loja do Shopping Patio Limeira e tive uma intoxicação alimentar!!! [...] (Jun/2014).

A empatia denota a capacidade da empresa de prestar um atendimento personalizado para o cliente, com cortesia e se adaptando a necessidades ou desejos particulares que cada consumidor possa apresentar. $\mathrm{O}$ atendimento recebeu um número grande de menções nos comentários analisados, sendo dez positivas e dezessete negativas, como representado na Tabela 4 e exemplificado com a extração da seguinte transcrição:

[...] Estou muito decepcionada com o atendimento do restaurante, sou cliente há anos e não esperava encontrar funcionários tão mal educados e despreparados. Espero que existam treinamentos e reciclagens para estes funcionários para que este tipo de comportamento não volte a se repetir. Lamentavelmente eu e meus amigos não voltaremos mais. Atendimento e ética zero. [...] (Jul/2014).

Tabela 4 - Resultados obtidos na categoria empatia

\begin{tabular}{llll}
\hline & Positivo & Negativo & Resultado \\
\hline Atendimento & 10 & 17 & -7 \\
Respeito/Educação & 2 & 4 & -2 \\
Adaptabilidade & 2 & 2 & 0 \\
\hline TOTAL & 14 & $\mathbf{2 3}$ & -9 \\
\hline
\end{tabular}

Fonte: Elaboração própria.

O respeito e a educação foram mencionados duas vezes de forma positiva e quatro de forma negativa, geralmente associados a um tratamento desrespeitoso em relação ao cliente, como no exemplo a seguir: 
[...] Um absurdo a loja da Miguel Lemos em Copacabana!!! Os pratos e talheres que nos oferecem estão sempre sujos, os vidros sempre imundos, as pessoas que atendem não tem nenhuma educação e se apresentam com o uniforme sujo. [...] (Set/2014).

A adaptabilidade apresentou um resultado neutro com duas menções positivas e duas negativas, como no exemplo a seguir:

[...] Boa noite pessoal, posso dar uma dica?Faça qualquer MASSA, mas antes se colocar no prato bote as torradas, tempere com as ervas q você goste, coloque um pouco de pimenta, azeite e o queijo ralado, pronto peça para o chef colocar a MASSA...HUMMMM! BOM APETITE [...] (Jun/2014).

Os tangíveis representam todas as pistas físicas que irão influenciar a percepção do consumidor. No caso de serviços híbridos como os de um restaurante, a refeição é um produto tangível. Esse agrupamento obteve dezesseis menções positivas e nove negativas, conforme Tabela 5 e exemplificado com o trecho transcrito a seguir:

[...] Quando chego no shopping Anália Franco, não resisto em apreciar a comida do restaurante, deliciosa e com uma equipe alto astral, preparada para um excelente atendimento. [...] (Ago/2014).

Tabela 5 - Resultados obtidos na categoria tangíveis

\begin{tabular}{lccc}
\hline & Positivo & Negativo & Resultado \\
\hline Produto & 16 & 9 & +7 \\
Padronização (Produto) & 0 & 5 & -5 \\
Padronização (Local) & 0 & 2 & -2 \\
\hline TOTAL & 16 & 16 & $\mathbf{0}$ \\
\hline
\end{tabular}

Fonte: Elaboração própria.

Já no aspecto da padronização do produto, os resultados apresentados foram de cinco comentários negativos, a maioria deles 
relativos a experiências anteriores dos consumidores que geraram expectativas que não foram atendidas em um novo encontro de serviço, como no exemplo a seguir:

[...] Sou viciada em massa... E almoço muito no restaurante... Porém tenho observado q esta cada dia mais difícil comer um macarrão ao SUGO... Qdo se pede ao sugo a pessoa espera não encontrar NENHUM pedaço de tomate... Muito menos cebola e algo verde q não é folha q não sei o q é... [...] Peneirem (sei lá) só façam q realmente o molho seja AO SUGO sem nenhum pedaço... Quem gosta de cebola e afins pede tarantela e não AO SUGO... [...] (Set/2014).

Observou-se, em relação à padronização do local, em que ocorre o encontro de serviços, dois comentários negativos referentes a diferenças encontradas entre franquias do mesmo restaurante, como no exemplo a seguir:

[...] Gente, o que acontece com os restaurantes da rede? Sempre adorei as massas, mas ontem e hoje estive em duas franquias diferentes e a percepção que tive foi a mesma: a quantidade de massa diminuiu, assim como a quantidade de molho. [...] E até o guardanapo, que estava vindo em duas unidades dentro de um saquinho plástico, agora vem um só, enrolando os talheres - por sinal bem mal lavados. Estou muito decepcionada com a falta de controle de qualidade das franquias! [...] (Jun/2014).

Os resultados encontrados apontam uma percepção negativa em quatro das cinco dimensões da qualidade percebida pelo consumidor, o que aponta para uma forte necessidade de mudança por parte da empresa para poder garantir a satisfação dos clientes.

Seguindo o modelo de lacunas proposto por Parasuraman, Berry e Zeithaml (1985) podemos identificar através da análise dos resultados que a lacuna um - da compreensão da empresa sobre o serviço esperado pelo consumidor - precisa ser fechada com uma preocupação constante em ouvir o consumidor, suas reclamações e sugestões. O procedimento 
exposto neste estudo demonstra uma forma de alcançar este objetivo. Através da análise criteriosa da comunicação dos consumidores nos sites de redes sociais, é possível aprender mais sobre suas expectativas e, no caso apresentado, suas frustrações em relação ao encontro de serviço. De posse dessas informações, a empresa tem condições de estreitar mais a lacuna da compreensão.

Alacuna dois - entre a percepção da empresa sobre as expectativas do cliente e o projeto de padrões de serviço - também precisa ser endereçada com maior padronização dos processos entre as mais de trezentas franquias do restaurante, evitando assim casos como a falta de ingredientes em muitas lojas, formas diferentes de atender e até mesmo diferenças na refeição, como apontado em alguns comentários.

A lacuna três - entre os padrões de serviço e sua execução deve ser resolvida com vistas a diminuir a inconstância no atendimento apontada em muitos comentários, o treinamento dos funcionários e um investimento no marketing interno, da empresa para os funcionários, e no marketing interativo, entre os funcionários e os clientes, (KOTLER; KELLER, 2012) deve ser priorizado.

A lacuna quatro - entre a comunicação e a execução do serviço - manifesta em comentários destacando as diferenças entre anúncios feitos pela empresa e o produto real, deve ser resolvida com a administração das expectativas dos clientes (KOTLER; KELLER, 2012), e com a preocupação constante em cumprir as promessas, sejam estas explícitas ou implícitas, como apontado por (ZEITHAML; BITNER; GREMLER, 2014).

Finalmente, a lacuna cinco ou lacuna do cliente - entre o serviço esperado e o serviço percebido - é, como apontado por Parasuraman, Berry e Zeithaml (1985), uma função das demais lacunas e os esforços em resolver os problemas nas quatro lacunas anteriores tem como consequência o fechamento da quinta lacuna.

Em última análise, é essencial que a empresa não trate as redes sociais apenas como mais um canal de comunicação externa com seus 
clientes, mas sim como fonte de informações sobre suas expectativas. Outra função nem sempre explorada é a da recuperação do serviço através das redes sociais, muitos comentários de clientes ficam sem resposta, promessas de contato telefônico não são cumpridas levando o cliente a retornar para as redes sociais e externar sua insatisfação também com a tentativa de recuperação.

No conjunto geral apresentado pela análise de resultados, a empresa está longe da percepção ideal sobre a qualidade de seus serviços por parte do consumidor. A concentração parece ser no produto final e nos aspectos tangíveis, não priorizando as questões ligadas ao encontro de serviços e a interação de funcionários e clientes, dessa interação surge a maioria dos problemas apontados pelos consumidores. A dificuldade maior parece residir na lacuna do desempenho entre os padrões de serviço da empresa e sua execução, e isso é agravado por se tratar de um sistema de franquias no qual possivelmente a estrutura verticalizada afaste ainda mais a linha de frente, responsável pela execução, da alta gerência da franqueadora, responsável pela definição dos padrões. Essa lacuna influencia a lacuna da comunicação, uma vez que a execução, fora dos padrões de serviço estabelecidos pela empresa, não consegue cumprir o prometido na comunicação. Influencia também a lacuna do cliente, já que em grande parte o serviço percebido pelo consumidor depende do desempenho da linha de frente na execução do serviço. A consequência é que o serviço percebido é pior do que o serviço esperado, gerando insatisfação.

\section{Considerações finais}

Os sites de redes sociais iniciaram uma verdadeira revolução no protagonismo do consumidor. Agora, influenciar nas decisões de compra, nas expectativas e nas percepções de centenas de pessoas está a um clique de distância. O setor de serviços é especialmente sensível a esse cenário uma vez que possui características de intangibilidade que aumentam muito suas características experimentáveis e por consequência, subjetivas. Mesmo serviços híbridos como os de 
restaurantes dependem da interação do cliente com funcionários para que seu produto seja consumido. O consumidor não avalia apenas o produto final, mas todo o processo.

O objetivo deste estudo foi alcançado ao demonstrar que a análise de conteúdo aplicada às mensagens, escritas pelos consumidores sobre a marca nos sites de redes sociais, contém informações sobre a qualidade de serviços percebida. Dessa forma, estar ciente desse conteúdo e de seus significados é essencial para empresas que desejam diminuir as lacunas da qualidade de serviços e assim aproximar o encontro de serviços às expectativas do consumidor.

A relevância do estudo é apoiada pela importância do setor de serviços e especialmente pela noção de que a diferenciação através da qualidade de serviços é um fator chave de sucesso para as empresas. Além disso, a escolha dos sites de redes sociais como meio para a coleta de dados se fez relevante na medida em que este espaço de comunicação mediada pelo computador tem permeado cada vez mais a nossa cultura, se mostrando como espaço rico para a disseminação de ideias e consequentemente de influência sobre as decisões de consumo.

Mesmo perante essa nova realidade, conceitos clássicos sobre marketing de serviços como aqueles presentes nos trabalhos de Parasuraman, Berry e Zeithaml(1985; 1988; 1991) permanecem tão válidos quanto antes, afinal na essência o encontro de serviços permanece o mesmo e com os mesmos desafios, o que muda é a amplitude que a má experiência de um consumidor pode alcançar em termos de comunicação com outros consumidores. Um cliente insatisfeito tem hoje um custo muito maior para a imagem da empresa e é neste aspecto que se identifica a necessidade de mudança mais drástica. As empresas não podem mais optar por ignorar as expectativas de seus clientes, para se manterem competitivas elas precisam adotar melhores práticas no gerenciamento da satisfação do consumidor. O Brasil ainda se apresenta precoce em seus indicadores globais de satisfação do cliente de serviços, isso demonstra que ainda há um longo caminho a 
percorrer até que o país perceba que seu bem-estar econômico depende em larga escala de uma melhora constante destes índices.

O resultado alcançado por esta pesquisa foi a reflexão sobre importância e benefícios das redes sociais nas organizações e suas relações com os consumidores. Uma nova ferramenta aliada para uma construção de uma boa comunicação e imagem organizacional no meio on-line. Como limitação do trabalho, aponta-se o período utilizado para coleta de dedos da análise e análise de um site. Os resultados obtidos não comportam generalizações, mas podem ser utilizados como base para novas pesquisas sobre tema abordado, incluindo sua replicabilidade para outras organizações, fomentando o conhecimento acerca dos fatos.

\section{Referências}

AAKER, D. A. Marcas: brand equity - gerenciando o valor da marca. São Paulo: Negócio Editora, 1998.

AGUIAR, S.. Redes sociais na internet: desafios à pesquisa. In: CONGRESSO BRASILEIRO DE CIÊNCIAS DA COMUNICAÇÃO: SOCIEDADE BRASILEIRA DE ESTUDOS INTERDISCIPLINARES DA COMUNICAÇÃO, 30, 2007, Santos. Anais... Sociedade Brasileira de Estudos Interdisciplinares da Comunicação. Santos: INTERCOM, 2007, p. 1-15.

BARDIN, Laurence. Análise de Conteúdo. São Paulo: Edições 70, 2011.

BOYD, D. M.; ELLISON, N. B. Social Network Sites: Definition, History, and Scholarship. Journal of Computer Mediated Communication, [S.I.], v. 13, n.1, p. 210-230, 2008.

BRITO, C.. Uma abordagem relacional ao valor da marca. Revista Portuguesa e Brasileira de Gestão. Rio de Janeiro, v.9, n.1-2, p. 4963, jan./jun., 2010. 
CIPRIANI, F.. Estratégias em mídias sociais. Rio de Janeiro: Campus. 2011.

COBRA, M. Administração de Marketing no Brasil. 3. ed. Rio de Janeiro: Elsevier, 2009.

DU, Q.; WANG, Q.; HUANG, D.; CAI, Y.; WANG, T.; MIN, H.

A relationship-based social question and answer system in social network. Journal of Information and Computational Science, [S.I.], v. 12, n.10, p.3783-3798, 2015.

FACI, N.; PETROCCHI, M.; COSTANTINO, G.; MARTINELLI, F.; MAAMAR, Z. A quality model for social networks populated with web services. Service Oriented Computing and Applications, [S.I.], v. 9, n. 2, p.139-155, June, 2015.

FTZSIMMONS, J. A.; FITZSIMMONS, M. J. Administração de serviços: operações, estratégia e tecnologia da informação. 4.ed. Porto Alegre: Bookman, 2005.

GIL, Antônio C. Métodos e Técnicas de Pesquisa Social. São Paulo: Atlas, 2008.

GRÖNROOS, C.. A service quality model and its marketing implications. European Journal of Marketing, [S.I.], v. 18, n. 4, p. 3644, Dec. 1984.

GRÖNROOS, C.. Marketing: gerenciamento e serviços. 3. ed. Rio de Janeiro: Elsevier, 2009.

INSTITUTO BRASILEIRO DE GEOGRAFIA E ESTATÍSTICA-IBGE. Pesquisa Anual de Serviços. Disponível em: <www.ibge.org.br>. Acessado em: 20 dez. 2014.

KELLER, K. L. Strategic Brand Management: building, measuring, and managing brand equity. Nova Jersey: Prentice Hall, 2003.

KIMES, S. E. The current state of online food ordering in the U.S. restaurant industry. Cornell Hospitality Report, [S.I.], v.11, n.17, p. 3448, Sept. 2011. 
KOTLER, P.; KELLER, K. L. Administração de Marketing. 12. ed. São Paulo: Pearson, 2012.

LOOMER, J.. Facebook ads costs up, performance down. 2012. Disponível em: < http://www.jonloomer.com/2012/04/16/tbg-facebookreport/tbg_infographic/>. Acesso em: 10 ago. 2014.

\section{Tbg-digital-global-facebook-advertising-report-q1-2012.}

Disponível em: < http://www.jonloomer.com/2012/04/16/tbg-facebookreport/tbg_infographic/>. Acesso em: 10 ago. 2014.

LOVELOCK, Christopher; WIRTZ, Jochen. Marketing de Serviços: pessoas, tecnologia e resultados. 5. ed. São Paulo: Pearson, 2006.

MARTENSEN, A.; GRONHOLDT, L.. Building Brand Equity: a customer-based modelling approach. Journal of Management Systems, [S.I], v. XVI, n. 3, p. 37-51, 2004.

NIELSEN. State of The Media: The Social Media Report 2012. Disponível em: <www.nielsen.com>. Acesso em: 20 nov. 2014.

NG, C.S.P; WANG, W.Y.C. Best Practices In Managing Social Media For Business. Thirty Fourth International Conference on Information Systems, Milan 2013. Disponível em: <https://www. researchgate.net/profile/Celeste_Ng/publication/262070915_ Best_practices_in_managing_social_media_for_business/ links/0deec5369cde5df526000000.pdf>. Acesso em: 10 ago. 2014.

OLIVER, Richard L. A Cognitive Model of Antecedents and Consequences of Satisfaction Decisions. Journal of Marketing Research, Chicago v. 17, n. 6, p. 460-469, Nov, 1980.

PARASURAMAN, A.; BERRY, L. L.; ZEITHAML, V. A. A Conceptual Model of Service Quality and Its Implications for Future Research. Journal of Marketing, Chicago, v. 49, n. 4 (Autumn), p. 41-50, 1985. . SERVQUAL: A Multiple-Item Scale For Measuring Consumer Perceptions of Service Quality. Journal of Retailing, [S.I], v. 64, n. 1, p. 12-40, Spring, 1988. 
. A. Refinement and Reassessment of the SERVQUAL Scale.

Journal of Retailing, [S.I], v. 67, n. 4, p. 420-450, spring 1991.

RECUERO, R. Diga-me com quem falas e dir-te-ei quem és: a conversação mediada pelo computador e as redes sociais na internet. Revista FAMECOS, Porto Alegre, n. 38, n. 1, p. 118-128, Abr. 2009. RECUERO, R.. Redes Sociais na Internet, Difusão de Informação e Jornalismo: Elementos para discussão, In: SOSTER, D.; FIRMINO, F. (Org.). Metamorfoses jornalísticas 2: a reconfiguração da forma. Santa Cruz do Sul: UNISC, 2009.

TORRES, C.. A Bíblia do Marketing Digital. 1. ed. São Paulo: Editora Novatec, 2009.

YIN, R. K. Estudo de caso: planejamento e métodos. Porto Alegre: Bookman, 2001.

ZEITHAML, V. A.; BITNER, M. J.; GREMLER, D. D. Marketing de serviços: a empresa com foco no cliente. Porto Alegre: Bookman, 2014.

Artigo recebido em: 08/01/2016

Aprovado em: 18/03/2016 